\title{
PENGARUH PENGALAMAN KERJA TERHADAP VOLUME PRODUKSI USAHA BATU BATA DI DESA SONOPATIK KABUPATEN NGANJUK
}

\author{
Dimas Sasongko Bhakti ${ }^{1}$, Sri Wahyuni ${ }^{1}$, Titin Kartini ${ }^{1}$ \\ ${ }^{1}$ Program Studi Pendidikan Ekonomi, Fakultas Keguruan dan Ilmu Pendidikan, Universitas Jember \\ E-mail: dimassasongkobhakti@gmail.com
}

\begin{abstract}
Abstrak
Penelitian ini brtujuan untuk mengetahui pengaruh yang signifikan pengalaman kerja terhadap volume produksi. Adapun penentuan lokasi penelitian menggunakan metode purposive area yaitu di Desa Sonopatik Kabupaten Nganjuk, sedangkan pengambilan sampel dilakukan dengan menggunakan metode Qouta Sampling dengan jumlah responden 80 pengrajin. Hasil penelitian menunjukkan bahwa pengalaman kerja memiliki pengaruh yang signifikan terhadap volume produksi usaha batu bata di Dea Sonopatik Kabupaten Nganjuk. Hasil Uji $\mathrm{F}$ menunjukkan $\mathrm{F}_{\text {hitung }}=323,820>\mathrm{F}_{\text {tabel }}=3,963$ dengan tingkat signifikansi 0,000 $<a=$ 0,05 dengan persamaan regresi sederhana $\hat{Y}=489.756+156.319 X$. Hasil perhitungan koefisien determinasi $\left(\mathrm{R}^{2}\right)$ sebesar 0,806 , hal ini menunjukkan bahwa besarnya persentase pengaruh Pengalaman kerja memiliki pengaruh yang signifikan terhadap volume produksi usaha batu bata di Dea Sonopatik Kabupaten Nganjuk sebesar $80,6 \%$, sedangkan sisanya yakni 19,4\% dipengaruhi oleh variabel bebas lain yang tidak diteliti dalam penelitian ini.
\end{abstract}

Kata Kunci: Pengalaman Kerja, Volume Produksi

\section{PENDAHULUAN}

Pertumbuhan di bidang properti saat ini semakin mengalami peningkatan. Salah satu bahan baku dalam pembuatan sebuah properti yaitu biasa digunakan sebagai bahan utama dalam pembuatan dinding rumah/gedung. Batu bata sering dipilih sebagai bahan alternatif penyusun bangunan karena harganya yang relatif murah, mudah diperoleh, memiliki kekuatan yang cukup tinggi, tahan terhadap pengaruh cuaca, dan tahan terhadap api.

Desa Sonopatik Kabupaten Nganjuk adalah salah satu setra pengrajin batu bata terdapat Di. Hampir semua warga yang ada di Desa Sonopatik memiliki usaha batu bata merah. Hingga saat ini sudah ada 660 kepala keluarga yang memiliki usaha batu bata merah. Usaha batu bata ini diawali karena kurangnya lapangan pekerjaan dan banyaknya pengangguran di desa tersebut, namun dengan adanya usaha ini mampu mengurangi jumlah pengangguran dan meningkatkan kesejahteraan ekonomi masyarakat di desa Sonopatik dan sekitarnya. Seiring berkembangnya waktu permintaan batu bata juga mengalami peningkatan, sehingga menuntut para produsen untuk meningkatkan volume produksi. Salah satu faktor penting dalam meningkatkan volume produksi adalah pengalaman kerja.

Pengalaman kerja adalah ukuran tentang lama waktu atau masa kerja yang telah ditempuh seseorang dapat memahami tugas - tugas suatu pekerjaan dan telah melaksanakan dengan baik. Dengan adanya pengalaman kerja maka telah terjadi proses penambahan ilmu pengetahuan dan ketrampilan serta sikap pada diri seseorang, sehingga dapat menunjang dalam mengembangkan diri dengan perubahan yang ada. Pengalaman kerja mempunyai pengaruh terhadap banyaknya produksi, besar kecilnya dan efisiensi yang dapat dilihat dari hasil volume produksi oleh tenaga kerja.

Pengalaman kerja yang dimiliki oleh pengrajin batu bata di Desa Sonopatik Kabupaten Nganjuk berbeda - beda mulai dari $<1$ tahun hingga lebih dari 10 tahun. Pada umumnya pengrajin yang memiliki pengalaman kerja lebih lama maka kemampuan kerja yang dimiliki juga lebih terampil dan cekatan, sehingga mampu menghasilkan volume produksi yang lebih banyak. Proses pembuatan batu bata ini sampai batu bata siap dijual membutuhkan waktu yang cukup lama, ini tergantung musim. Pada musim panas memerlukan waktu 10 hari untuk membuat batu bata sampai siap untuk digunakan oleh konsumen, namun jika musim hujan bisa memakan waktu 2 minggu bahkan lebih untuk pembuatan batu bata sampai siap untuk diedarkan. Berdasarkan informasi dari produsen batu 
bata produksi bisa mencapai 6000 biji/hari oleh pengrajin yang sudah memiliki pengalaman kerja yang cukup lama

Berdasarkan pemaparan di atas, maka peneliti bermaksud mengadakan penelitian yang bertujuan untuk mengetahui pengaruh yang signifikan Pengalaman kerja terhadap volume produksi Desa Sonopatik Kabupaten Nganjuk.

\section{METODE}

Penelitian ini dilakukan dengan metode kuantitatif menggunakan analisis regresi linier sederhana. Adapun metode penentuan lokasi penelitian menggunakan purposive area dan penentuan sampel menggunakan qouta sampling, yakni pengrajin batu bata di Desa Sonopatik Kabupaten Nganjuk dengan jumlah responden 80 pengrajin. Metode pengumpulan data menggunakan kuesioner terbuka, dan wawancara terstruktur. Analisis data yang digunakan adalah uji validitas, uji reliabilitas, varian garis regresi, Uji F, dan koefisien determinasi, untuk memudahkan perhitungan analisis data maka peneliti menggunakan bantuan program SPSS 22.0 for windows.

\section{HASIL DAN PEMBAHASAN \\ Hasil Penelitian}

\section{a. Uji Validitas Penelitian}

Hasil uji validitas terhadap data dalam penelitian ini adalah sebagai berikut:

Tabel 4.5 Hasil Uji Validitas Variabel Pengalaman Kerja(X) dan Volume Produksi (Y)

\begin{tabular}{|l|l|l|l|l|}
\hline No. & Item Pertanyaan & Pearson Correlation & Sig. & Kesimpulan \\
\hline 1. & $\mathrm{X}$ & 0,899 & 0,000 & Valid \\
\hline 2. & $\mathrm{Y}$ & 1,000 & 0,000 & Valid \\
\hline
\end{tabular}

Sumber : Data Primer diolah (2019)

Berdasarkan Tabel tersebut, dapat diketahui bahwa semua pengujian terhadap variabel $\mathrm{X}$ yaitu variabel pengalaman kerja dan variabel $\mathrm{Y}$ yaitu volume produksi menunjukkan bahwa seluruh data yang diperoleh adalah valid. Hal tersebut memenuhi persyaratan nilai signifikansi $<0,05$, dengan demikian semua butir pertanyaan dalam kuesioner tersebut dapat digunakan dan dapat dipercaya sebagai data penelitian ini.

\section{b. Uji Reliabilitas Penelitian}

Tabel 4.6 Hasil Uji Reliabilitas

\begin{tabular}{|l|l|l|l|}
\hline No. & Variabel & Cronbach alpha & Keterangan \\
\hline 1. & X dan Y & 0,754 & Reliabel \\
\hline
\end{tabular}

Sumber : Data Primer Diolah (2019)

Berdasarkan uji reliabilitas di atas, suatu instrumen atau angket dari variabel pengalaman kerja $(\mathrm{X})$ dan variabel volume produksi $(\mathrm{Y})$ terbukti reliabel, dikarenakan nilai pengalaman kerja $(\mathrm{X})$ sebesar 0,754 dan variabel volume produksi (Y) sebesar 0,754 yang lebih besar dari 0,6. Hal ini membuktikan hasil penelitian cukup dapat dipercaya dan sesuai dengan kenyataannya, dan hasilnya tetap sama meskipun angket disebarkan sebanyak dua kali kepada responden.

\section{c. Analisis Garis Regresi Sederhana}

Analisis garis regresi sederhana digunakan untuk mengetahui pengaruh antara variabel pengalaman kerja (X) terhadap volume produksi usaha batu bata di Desa Sonopatik Kabupaten Nganjuk (Y). Pada penelitian ini, dilakukan analisis garis regresi sederhana dengan menggunakan program SPSS 22.0 for windows. Hasil analisis garis regresi sederhana disajikan pada tabel berikut ini:

Tabel 4.7 Hasil Analisis Garis Regresi Sederhana 


\begin{tabular}{l|l|l}
\hline Variabel Penelitian & Label & Koefisien Regresi \\
\hline $\mathrm{A}$ & Konstanta & -489.756 \\
\hline $\mathrm{X}$ & Pengalaman Kerja & 156.319 \\
\hline Rsquare $=0,806$ & \\
Multiple R $=0,898^{\mathrm{a}}$ & \\
\hline
\end{tabular}

Sumber: Data Primer diolah (2019)

Berdasarkan tabel tersebut, maka persamaan garis regresi sederhana yang diperoleh dalam penelitian ini adalah sebagai berikut:

$$
\hat{Y}=-489.756+156.319+\text { ei }
$$

\section{d. Analisis Varian Garis Regresi}

Analisis ini digunakan untuk mengetahui kuat tidaknya atau untuk mengetahui tingkat keeratan komponen pengalaman kerja (X) terhadap volume produksi usaha batu bata di Desa Sonopatik Kabupaten Nganjuk (Y). Adapun besarnya varian garis regresi antara variabel bebas (X) dan variabel terikat (Y) dapat dilihat pada tabel berikut:

Tabel 4.8 Rekapitulasi Pengalaman KerjaTerhadap Volume Produksi

\begin{tabular}{|l|l|}
\hline \multicolumn{1}{|c|}{ Variabel } & \multicolumn{1}{|c|}{$\mathrm{R}$} \\
\hline $\begin{array}{l}\text { Pengaruh pengalaman kerja(X) terhadap volume } \\
\text { produksi(Y) }\end{array}$ & 0,806 \\
\hline
\end{tabular}

Sumber: Data Primer Diolah (2019)

Berdasarkan perhitungan di atas dapat diketahui bahwa nilai koefisisen korelasi sebesar 0,806 berarti bahwa pengalaman kerja $(\mathrm{X})$ memiliki hubungan yang nyata/signifikan dengan volume produksi usaha batu bata di Desa Sonopatik Kabupaten Nganjuk (Y). Tingkat hubungan tersebut dapat dikategorikan sebagai hubungan yang sangat kuat.Tabel yang menunjukkan interpretasi terhadap koefisien korelasi bisa terlihat sebagai berikut yang digunakan sebagai interpretasi terhadap koefisien korelasi.

\section{e. Uji F}

Berdasarkan perhitungan hasil SPSS 22.0 for windows, diketahui nilai $\mathrm{F}_{\text {hitung }}$ sebagai berikut: Tabel 4.10 Rekapitulasi Hasil SPSS Untuk Uji F

\begin{tabular}{|c|c|c|c|c|}
\hline Variabel & $\mathrm{F}_{\text {hitung }}$ & $\mathrm{F}_{\text {tabel }}$ & $\mathrm{a}$ & Sig. F \\
\hline $\mathrm{X}$ terhadap $\mathrm{Y}$ & 323,820 & 3,963 & 0,05 &, 000 \\
\hline
\end{tabular}

Sumber: Data Primer (2019), diolah

Berdasarkan tabel di atas, diketahui bahwa besarnya $\mathrm{F}_{\text {hitung }}=323,820>\mathrm{F}_{\text {tabel }}=3,963$ dengan tingkat signifikansi $\mathrm{F}=0,000<a=0,05$. Hal ini menunjukkan bahwa variabel pengalaman kerja memiliki pengaruh yang signifikan terhadap volume produksi usaha batu bata di Desa Sonopatik Kabupaten Nganjuk. Berdasarkan data tersebut dapat disimpulkan bahwa Ho ditolak dan Ha diterima yaitu ada pengaruh yang signifikan variabel pengalaman kerja terhadap volume produksi usaha batu bata di Desa Sonopatik Kabupaten Nganjuk.

\section{f. Efektififitas Garis Regresi $\left(\mathbf{R}^{2}\right)$}

Efektifitas garis regresi digunakan untuk mengukur besarnya proporsi sumbangan variabel bebas (X) terhadap variabel terikat (Y). Hasil SPSS 22.0 for windows diperoleh nilai koefisien determinasi ( $\left.\mathrm{R}_{\text {square }}\right)$ sebesar 0,806 .

$$
\mathrm{R}_{\text {square }} \mathrm{X} 100 \%=0,806 \times 100 \%=80,6 \%
$$

Hal ini menunjukkan bahwa besarnya persentase pengalaman kerja terhadap volume produksi usaha batu bata di Desa Sonopatik Kabupaten Nganjuk sebesar 80,6\%. sedangkan sisanya yaitu $19,4 \%$ dipengaruhi variabel bebas lainnya yang tidak diteliti dalam penelitian ini. 


\section{Pembahasan}

Hasil penelitian menunjukkan bahwa ada pengaruh yang signifikan pengalaman kerja terhadap volume produksi usaha batu bata di Desa Sonopatik Kabupaten Nganjuk. Hal ini artinya hipotesis tersebut terjawab secara simultan pengalaman kerja berpengaruh terhadap volume produksi sebesar $80,6 \%$ sedangkan sisanya yaitu 19,4\% dipengaruhi variabel bebas lainnya yang tidak diteliti dalam penelitian ini.. Jadi dapat diketahui pengalaman kerja memiliki pengaruh yang signifikan terhadap volume produksi usaha batu bata di Desa Sonopatik Kabupaten Nganjuk.

Pengalaman kerja merupakan hal yang sangat penting yang berkaitan erat dengan volume produksi suatu usaha. Hal ini dikarenakan pengalaman kerja adalah proses pembentukan pengetahuan atau keterampilan tentang metode suatu pekerjaan karena keterlibatan karyawan tersebut dalam pelaksanaan tugas pekerjaan. Dimana pengalaman kerja dalam penelitian ini yaitu lama kerja dari pemilik usaha batu bata di Desa Sonopatik Kabupaten Nganjuk dalam menjalankan usaha pembuatan batu bata tersebut

Pengalaman kerja seseorang juga dapat diukur atau ditentukan dari lama waktu seseorang itu bekerja. Semakin lama tenaga kerja bekerja, makin banyak pengalaman yang dimiliki tenaga kerja yang bersangkutan. Sebaliknya, semakin singkat masa kerja, makin sedikit pengalaman yang diperoleh. Pengalaman bekerja banyak memberikan keahlian dan keterampilan kerja. Sebaliknya, terbatasnya pengalaman kerja mengakibatkan tingkat keahlian dan keterampilan yang dimiliki makin rendah. Ukuran tentang lama waktu atau masa kerja yang telah ditempuh seseorang dapat memahami tugas - tugas suatu pekerjaan dan telah melaksanakan dengan baik.

Semakin lama tenaga kerja bekerja, semakin banyak pengalaman yang dimiliki tenaga kerja yang bersangkutan. Sebaliknya, makin singkat masa kerja, makin sedikit pengalaman yang diperoleh (Sastrohadiwiryo, 2005). Pengalaman bekerja yang dimiliki seseorang seperti halnya para pengrajin batu bata di Desa Sonopatik Kabupaten Nganjuk, lebih memiliki nilai daripada seseorang yang berpendidikan tinggi. Pengalaman bekerja merupakan modal utama seseorang untuk terjun dalam bidang tertentu. Tenaga kerja yang berpengalaman dapat langsung menyelesaikan tugas dan pekerjaannya.

Berikut merupakan hasil wawancara yang dilakukan peneliti dengan salah satu pengrajin batu bata di Desa Sonopatik Kabupaten Nganjuk yang menjadi responden dalam penelitian ini.

"Pengalaman kerja sangat penting mas, karena dengan pengalaman yang banyak dalam

membuat batu bata maka dapat menghasilkan batu bata dengan cepat, banyak, serta berkualitas" (AL, $\left.71^{\text {Th}}\right)$.

Berdasarkan pendapat di atas, dapat diketahui bahwa pengalaman kerja merupakan hal yang sangat penting yang harus diperhatikan oleh pemilik usaha batu bata di Desa Sonopatik Kabupaten Nganjuk. Hal ini dikarenakan dengan pengalaman kerja atau masa kerja yang lama, maka akan dapat menghasilkan produk batu bata dengan jumlah yang banyak serta batu bata yang berkualitas baik. Jadi pengalaman kerja (lama kerja) para pengrajin batu bata di Desa Sonopatik Kabupaten Nganjuk sangat mempngaruhi volume produksi batu bata yang dihasilkan. Volume produksi menurut Kotler (2008:203) merupakan barang yang terproduksi untuk jangka waktu tertentu dan didalamnya mempunyai strategi pelayanan yang baik.

Volume produksi batu bata yang duhasilkan oleh pengrajin batu bata di Desa Sonopatik Kabupaten Nganjuk merupakan hasil dari suatu kegiatan pekerjaan membuat batu bata yang dilakukan oleh pekerja baik yang berpengalaman maupun tidak, dimana seseorang yang berpengalaman maka akan lebih memiliki keterampilan dan pengetahuan yang lebih, sehingga akan berpengaruh positif terhadap hasil produksi. Selain itu para pekerja yang berpengalaman dikarenakan sudah lama bekerja akan dapat menghasilkan batu bata yang lebih banyak daripada pekerja yang masih baru.

Hal ini sesuai dengan pendapat Sinungan (2010:2), yang menjelaskan bahwa pencapaian volume produksi dapat dipengaruhi oleh beberapa factor yaitu faktor kompensasi, faktor kemampuan kerja, pengalaman kerja, faktor lingkungan, dan faktor motivasi kerja. Volume produksi dapat dipengaruhi oleh karywan atau pekerja atau disebut Human factor, salah satunya pengalaman kerja (Sarwoto, 2002:141).Berikut merupakan hasil wawancara yang dilakukan peneliti dengan salah satu 
pengrajin batu bata di Desa Sonopatik Kabupaten Nganjuk yang menjadi responden dalam penelitian ini.

“.................ada pengaruh pengalaman kerja dengan volume produksi mas, karena dengan semakin lama dan banyak pengalaman kerja yang dimiliki maha hasil batu bata yang dihasilkan juga akan semakin banyak mas, sebaliknya jika pengalaman kerja yang dimiliki masih sedikit, biasanya batu bata yang dihasilkan juga lebih sedikit" (AL, $\left.71^{\mathrm{Th}}\right)$.

Berdasarkan pendapat dari responden tersebut nampak jelas bahwa pengrajin yang sudah lama bekerja akan memiliki keterampilan yang tinggi tentang pembuatan batu bata, sehingga volume produksi batu bata yang dihasilkan juga akan tinggi. Sebaliknya jika pengrajin baru maka pengalaman yang diperoleh masih sedikit sehingga kuantitas batu bata yang dihasilkan biasanya juga masih sedikit. Pengalaman merupakan faktor utama dalam perkembangan seseorang, sedangkan pengalaman hanya mungkin diperoleh dalam hubungan lingkungannya. Semakin lama masa kerja karyawan pada sebuah perusahaan, maka semakin banyak pula pengalaman yang ia dapatkan. Dengan pengalaman kerja yang banyak, maka tingkat produktivitas yang dihasilkanpun juga akan semakin tinggi (Sedarmayanti, 2001:68).

\section{PENUTUP}

Berdasarkan hasil penelitian dan pembahasan mengenai pengaruh pengalaman kerja terhadap volume produksi usaha batu bata di Desa Sonopatik Kabupaten Nganjuk, dapat disimpulkan bahwa ada pengaruh yang signifikan pengalaman kerja terhadap volume produksi usaha batu bata di Desa Sonopatik Kabupaten Nganjuk. Besarnya persentase pengaruh pengalaman kerja terhadap volume produksi usaha batu bata di Desa Sonopatik Kabupaten Nganjuk adalah 80,6\%.

Berdasarkan kesimpulan di atas, maka penulis memberikan saran kepada Bagi pihak pengrajin batu bata di Desa Sonopatik Kabupaten Nganjuk, sebaiknya terus meningkatkan volume produksi. serta memberikan pengetahuan tambahan kepada para pengrajin pemula berkaitan dengan pembuatan batu bata.Bagi para pengrajin, hendaknya lebih memaksimalkan dalam membuat batu bata agar dapat menghasilkan batu bata yang memenuhi tarjet serta batu bata yang berkualitas. Bagi peneliti lain, diharapkan bagi peneliti lain yang akan melakukan penelitian serupa dengan penelitian ini untuk mengambil variabel lain yang tidak turut diteliti dalam penelitian ini, supaya dapat menciptakan penelitian-penelitian yang lebih baik dan nantinya sebagai tambahan referensi penelitian yang sejenis.

\section{DAFTAR PUSTAKA}

Hani, Handoko T. 2007. Manajemen Personalia dan Sumber Daya Manusia. BPFE : Yogyakarta.

Hasan, M. Iqbal. 2003. Pokok - Pokok Materi Statistik 1(Statistik Deskriptif). Edisi Kedua, Hal 220. Penerbit PT. Bumi Aksara : Jakarta.

Kotler, Philip. 2008. Manajemen Pemasaran. Edisi 12 Jilid 2, Hal 203. Indeks : Jakarta.

Machfoedz. M. 2007. Pengantar Bisnis Modern. Edisi 1, Hal 101. Andi : Yogyakarta.

Manullang. 2004. Manajemen Personalia. Edisi Ketiga : Hal 15. UGM : Yogyakarta.

Ranupandojo. 2004. Manajemen Sumber Daya Manusia. BPFE, Hal 71 : Yogyakarta.

Sarwoto. 2002. Dasar - Dasar Organisasi Management. Ghalia Indonesia, Hal 141 : Jakarta. 
Sastrohadiwiryo, Siswanto, B. 2005. Manajemen Tenaga Kerja Indonesia Pendekatan Administratif dan Operasional. Bumi Aksara : Jakarta.

Sedarmayanti. 2001. Sumber Daya Manusia dan Produktivitas Kerja. Mandar Maju, Hal 68 : Bandung.

Sinungan, Muchdarsyah. 2010. Produktivitas Apa dan Bagaiman. Mandar Maju : Bandung.

Siswanto. 2002. Manajemen Tenaga Kerja. Sinar Baru, Hal 163 : Bandung.

Sugiyono, 2001. Metode Penelitian. CV Alfa Beta. Hal 60 : Bandung. 